\title{
Erratum to: Teachers' Use of Focus Questions in German Biology Classrooms: a Video-Based Naturalistic Study
}

\author{
Jigna Nawani ${ }^{1} \cdot$ Lena von Kotzebue ${ }^{1}$. \\ Julia Rixius $^{1}$ • Michael Graml ${ }^{1}$ • Birgit J. Neuhaus ${ }^{1}$
}

Published online: 18 September 2017

(C) Ministry of Science and Technology, Taiwan 2017

\section{Erratum to: Int $\mathbf{J}$ of Sci and Math Educ \\ https://doi.org/10.1007/s10763-017-9837-z}

Because of a mistake in the editorial process Lena Kotzebue, Julia Rixius, Michael Graml, and Birgit J. Neuhaus were not included as authors of this article in the initial online publication. The original article has now been corrected.

The online version of the original article can be found at https://doi.org/10.1007/s10763-017-9837-z

Jigna Nawani

Jigna.Nawani@biologie.uni-muenchen.de

1 Institute of Biology Education, Faculty of Biology, Department I, LMU Munich, Munich, Germany 